\title{
Riesgo biológico en el aire respirable de los minadores de basura en la E†2 Zámbiza en Quito-Ecuador*
}

\section{Risk in the Breathable Air of the Garbage Miners in the TS2 Zambiza in Quito-Ecuador}

\author{
K. Coral**, M. A. Rodríguez ${ }^{* * *}$, J. E. Oviedo**** \\ Recibido: 2017-02-10 // Aprobado: 2017-04-05// Disponible en linea: 2017-06-30
}

Cómo citar este artículo: Coral, K., Rodríguez, M. A. y Oviedo, J. E. (2017). Riesgo biológico en el aire respirable de los minadores de basura en la Et2 Zámbiza en Quito-Ecuador. Ambiente y Desarrollo, 21(41), 79-92. https://doi.org/10.11144/Javeriana.ayd21-41.rbar doi:10.11144/Javeriana.ayd21-41.rbar

\section{Resumen}

La ciudad de Quito dispone de dos estaciones de transferencia de residuos, previamente a su transporte al relleno sanitario de El Inga. En la estación de transferencia de Zámbiza laboran minadores recolectando el material reciclable de los residuos, labor que los pone directamente en contacto con los residuos de papel higiénico cargados de heces humanas que la comunidad desecha junto con los residuos, exponiéndolos a un riesgo biológico que ha sido evaluado a través de la determinación de coliformes fecales y totales en su ambiente de trabajo y la posterior aplicación del método Biogaval. Se obtuvo que los minadores superan el nivel de acción biológica para la tifoidea y paratifoidea y están muy cerca en el caso de intoxicaciones alimentarias con presencia de diarreas agudas. Con las medidas correctivas se logró disminuir el riesgo hasta niveles inferiores al inicial.

Palabras clave: partículas atmosféricas; organismos patógenos; desechos urbanos; riesgos para la salud

\footnotetext{
Este artículo surge del proyecto de investigación Valoración energética de los RSU del DMQ, desarrollado por la Universidad Internacional SEK del Ecuador.

** MSc, Ing. Química, Universidad Internacional SEK, Facultad de Ciencias Naturales y Ambientales, Quito, Ecuador. Docente de la Universidad de Cantabria, Escuela de Ingenieros Industriales, Grupo QuiPre, Santander. Doctoranda. Correo electrónico: katty_coral@hotmail.com

**** MSc, Ing. Química, Universidad de Cantabria, Escuela de Ingenieros Industriales, Grupo QuiPre, Santander. Doctoranda. Correo electrónico: alurod@hotmail.com

***** MSc, Ing. Ambiental, Universidad de Cantabria, Escuela de Ingenieros Industriales, Grupo QuiPre, Santander. Doctorando. Correo electrónico: alurod@hotmail.com
} 


\begin{abstract}
The city of Quito has two transfer stations for waste before it is transported to the El Inga landfill. At the Zámbiza transfer station, miners collect the recyclable material from the waste, which puts them directly in contact with the waste of toilet paper loaded with human feces that the community discards together with the waste. This exposes them to a biological risk that has been evaluated through the determination of fecal and total coliforms in their work environment and the subsequent application of the Biogaval method. The results obtained show that the miners surpass the level of biological action for the typhoid and paratyphoid fever and are very close in the case of food poisoning with the presence of acute diarrhea. Corrective measures reduced the risk to levels lower than the initial one.
\end{abstract}

Keywords: atmospheric particles; pathogenic organisms; urban waste; health risks 


\section{Introducción}

La Empresa Pública Metropolitana de Aseo (Emaseo) es la empresa municipal que tiene a su cargo la recolección de residuos domésticos, así como el barrido de calles, plazas, vías y espacios públicos del Distrito Metropolitano de Quito (DMQ), capital del Ecuador (Emaseo, 2010).

La recolección de residuos sólidos urbanos (RSU) se realiza a pie de vereda o por contenerización mediante vehículos recolectores (Emaseo, 2010). Los residuos provenientes de la recolección son llevados a las estaciones de transferencia Zámbiza/Porotohuaico (ET2), ubicada en el norte de la ciudad, y Santa Rosa (ET1), ubicada en el sur de la ciudad; desde allí son transportados al relleno sanitario El Inga 2 para su disposición final. Las estaciones funcionan las veinticuatro horas del día, los 365 días del año.

En la estación de transferencia de Zámbiza ET2 se formó un grupo de minadores llamado Asociación de Gestores Artesanales Nueva Vida, compuesto por aproximadamente 220 personas dedicadas al reciclaje de papel, cartón, plástico, metal y vidrio, que generan alrededor de US $\$ 80$ semanales de ingresos con el reciclaje, de los cuales aportan US $\$ 0.02$ a la asociación por kilo recogido (EMGIRS EP, 2013). Los minadores, también llamados gestores ambientales artesanales (GAA), clasifican y reciclan la basura de forma precaria y con riesgo a su salud, lo que los convierte en un grupo vulnerable digno de ser estudiado bajo la lupa de los riesgos ocupacionales, principalmente el biológico.

Los minadores de la ET2 Zámbiza trabajan entre seis y ocho horas diarias abriendo las fundas de basura recolectadas en el sector norte del DMQ. Una vez abiertas las fundas, recolectan aquellos materiales que pueden ser aprovechados o comercializados. En este proceso, dejan al descubierto los papeles higiénicos que transportan las fundas de residuos domésticos. El movimiento que provoca la búsqueda de materiales recuperables libera al ambiente partículas de papel sanitario que contienen heces y que forman parte de la basura normal de los quiteños, lo que hace suponer la presencia de patógenos en el aire respirable, principalmente coliformes totales y fecales, los cuales forman lo que se denomina "bioaerosoles" (INSHT NTP 608, 2005). A pesar de lo descrito, no se ha realizado hasta el momento ningún estudio sobre la calidad del aire en su ambiente laboral, desde el punto de vista de riesgo biológico.

De todos los aspectos ambientales en los que se desenvuelve cualquier trabajador, el más importante es la calidad de aire respirable, debido a que la respiración es un proceso natural de vida que no puede interrumpirse bajo ninguna consideración y que se acelera cuando se efectúan labores que requieren esfuerzo físico, como es el caso de los minadores.

Los bioaerosoles sedimentan en las superficies de los lugares de trabajo y los contaminan. En el caso de la ET2, la contaminación microbiológica proviene de las superficies donde se vuelven a depositar. Por lo tanto, el riesgo biológico para los minadores se presenta no solo en el aire respirable, sino también en los elementos de contacto (residuos), manos, rostros, ropa de trabajo e incluso comida con la que los trabajadores pudieran estar en contacto.

Según la Agencia Europea para la Seguridad y Salud en el Trabajo (2007), los estudios epidemiológicos a escala mundial indican que cientos de millones de personas de todo el mundo se encuentran expuestas a agentes biológicos, por lo que se ha convertido no solo en un problema de salud pública, sino también en una cuestión importante para la medicina laboral.

Los riesgos biológicos son causados por organismos vivos que pueden dar lugar a enfermedades infecciosas o parasitarias. Por su naturaleza de agentes vivos, se diferencian de otros agentes causantes de enfermedades en ambientes laborales porque comparten con el cuerpo humano su conformación a base de células. Estos agentes se pueden transmitir por contacto físico directo, inhalación, ingestión o inyección. La exposición laboral a riesgos biológicos es mayor dependiendo del trabajo que se realice. Y los trabajos que se consideran con mayor riesgo biológico son, entre otros: laboratorios clínicos, hospitales en diferentes áreas, camales, crianza de animales, procesamiento de alimentos, recogida y clasificación de residuos (Rodellar, 1999). 
El Instituto Valenciano de Seguridad y Salud en el Trabajo (Invassat) de España define a Biogaval como un método práctico de evaluación del riesgo biológico en actividades laborales diversas. Su objetivo primordial es proporcionar una herramienta que permita evaluar de una forma eficaz la exposición a agentes biológicos de los trabajadores. A lo largo de los años, esta herramienta ha demostrado su utilidad y practicidad, no solo en Espańa, sino también en el ámbito latinoamericano.

Biogaval (2013) indica que una de las ocupaciones laborales que presentan riesgo biológico es la eliminación de residuos. Y las enfermedades más comunes en este tipo de trabajadores son la tifoidea, la paratifoidea y la disentería bacteriana, las cuales se producen por las bacterias coliformes. Sin embargo, los coliformes no son el único peligro en este tipo de actividad, existe una gran y variada cantidad de agentes biológicos tales como estafilococos, estreptococos, shigella, amebas y hongos, entre otros. Esta investigación se centra en las bacterias coliformes, aunque posteriormente puede ampliarse a otros microorganismos.

\section{Materiales y métodos}

\section{Muestreo}

La presente investigación determinó la presencia de bacterias coliformes totales y fecales en el aire respirable de la estación de transferencia de Zámbiza ET2. Se recolectó en cajas Petri, con medios de cultivo adecuados. El bioaerosol presente en las áreas críticas de la zona de trabajo, a través de un proceso de precipitación. El monitoreo se realizó en las horas pico de operación de transferencia de la basura en la ET2, esto es, a las 9h00 en la mañana y a las $18 \mathrm{~h} 00$ en la tarde-noche, en los puntos críticos que se localizaron en un primer muestreo de sondeo.

Se tomó una muestra semanal durante un periodo de cinco meses (agosto a diciembre del 2015). La variable independiente fue la condición de trabajo (residuos contaminados, cantidad, tiempo de exposición) a la que están expuestos los minadores en la jornada laboral, en tanto que las variables dependientes fueron las bacterias coliformes totales y fecales presentes en el aire respirable, producto de la manipulación de los residuos domésticos que llegan a la estación.

Se estableció como población total los días que trabajan los minadores en la estación de transferencia ET2 Zámbiza, donde se procesa basura los 365 días del año. Los minadores operan ocho horas por día, equivalentes a un tercio de día, con lo cual la población total se reduce a 122 días del año. El número de muestras representativo por obtenerse se estableció en 52.

\section{Determinación cualitativa de coliformes totales y fecales}

Se realizó en la planada de clasificación de residuos de la estación de transferencia de Zámbiza, ET2. Cada determinación se efectúo en tres puntos críticos de la ET2, ubicados en el perímetro de la planada, y para ello fue indispensable realizar un primer barrido con ocho puertos de muestreo en los muelles de la planada, a fin de determinar los puntos críticos en los que se desarrolló el monitoreo. Para que la muestra sea representativa, el muestreo se realizó en el momento de arribo de los camiones recolectores a la planada de la ET2, arribo en el que se deposita la basura en el rellano y los minadores inician su labor.

La determinación utilizó el método de sedimentación, el cual, de acuerdo con Dónate et al. (2000), es el método más sencillo de determinación de microorganismos en el ambiente. Consiste en la exposición de cajas Petri con agar nutritivo al medio durante treinta minutos. Las partículas y los microorganismos en suspensión se depositan en ellas por sedimentación, es decir, por efecto de la fuerza gravitacional sobre el material particulado suspendido. La principal ventaja del método es que se puede aplicar en una variedad infinita de condiciones rutinarias de trabajo y en tiempo real, es muy económico y requiere poco tiempo de recolección. Este análisis bacteriológico se reporta en unidades formadoras de colonias (UFC)/hora. 
Las unidades hacen referencia al tiempo de exposición de las cajas Petri. El método no puede referirse a un volumen específico de aire, ya que no es una variable que sea medida. Por lo tanto, los resultados no pueden ser cuantitativos, sino únicamente cualitativos. Un aspecto fundamental en este tipo de análisis es que la exposición de la caja Petri con el agar nutritivo no puede ser extremadamente larga (periodos mayores a treinta minutos), ya que la superficie de agar en la placa puede resecarse (Dónate et al., 2000).

Para la determinación de coliformes totales se utilizó el método de tinción. En este proceso las moléculas de un colorante se adsorben a una superficie. El uso de colorantes permite cambiar el color de las células de los microorganismos para poder observarlas, ya que, naturalmente, las bacterias son casi incoloras, no presentan contraste con el medio en el cual se encuentran suspendidas y no pueden observarse claramente sin algún tratamiento previo (Esteban, 2012).

De acuerdo con Koneman y Allen (2008), los coliformes totales son bacterias con forma de bastones, no forman esporas, son Gram negativos aerobios y anaerobios facultativos. Para su determinación se aplica el método de tinción de Gram, que permite, de acuerdo con la estructura y grosor de la pared bacteriana, agrupar las bacterias en Gram positivas y Gram negativas (Rodríguez et al., 2005). En este proyecto no se utilizaron muestreadores de aire ambiental (surface air system), debido a que este sistema requiere medios de cultivo específicos para los contaminantes previamente identificados, lo que en este primer acercamiento al riesgo biológico en Zámbiza resulta inviable.

\section{Aplicación del Biogaval}

La siguiente es la clasificación de los agentes biológicos en función de su riesgo de infección (INSL, 2013):

- Agente biológico del grupo 1: es aquel que resulta poco probable que cause una enfermedad en los seres humanos.

- Agente biológico del grupo 2: puede causar una enfermedad en el hombre y asimismo suponer un peligro para los trabajadores. Es poco probable que se propague a la colectividad y generalmente existe profilaxis o tratamiento eficaz.

- Agente biológico del grupo 3: puede causar una enfermedad grave en el hombre y presenta un serio peligro para los trabajadores, con riesgo de que se propague a la colectividad. Por lo general, existe una profilaxis o tratamiento eficaz.

- Agente biológico del grupo 4: aquel que causa una enfermedad grave en el hombre y supone un serio peligro para los trabajadores, con muchas probabilidades de que se propague a la colectividad. No existe, generalmente, una profilaxis o un tratamiento eficaz.

Con los datos obtenidos se procedió a realizar la evaluación del riesgo biológico al que se exponen los minadores, aplicando el método Biogaval (2013), que consiste en:

A. Determinación de los puestos por evaluar. En el caso de los minadores se establecerán los puntos críticos de monitoreo en la planada de la ET2.

B. Identificación del agente biológico implicado. En este caso se aplicarán los resultados obtenidos en el análisis experimental previamente realizado.

C. A continuación se procederá a la cuantificación de las variables determinantes del riesgo:

C.1 Clasificación del daño, para lo cual se determinará la enfermedad más común que podrían padecer los minadores como consecuencia de su exposición a coliformes totales y fecales, esto es, la tifoidea e intoxicaciones alimentarias (diarreas agudas). Posteriormente, se aplica la tabla respectiva del Biogaval.

C.2 En este caso se considerará siempre la vía de transmisión aérea.

C.3. Tasa de incidencia del ańo anterior. Para la aplicación de este valor, y al no existir estadísticas para los minadores, se aplicarán los datos nacionales establecidos por el INEC o del Ministerio de Salud. 
C.4. Para evaluar la vacunación se acogerán igualmente los datos del Instituto Nacional de Estadística y Censos (INEC) o del Ministerio de Salud, así como lo estipulado en el Biogaval.

C.5. La frecuencia de realización de tareas de riesgo responderá a visualización in situ.

C.6. Las medidas higiénicas adoptadas se evaluarán a través de una verificación directa en la ET2.

C.7. Se procederá con el cálculo del nivel de riesgo biológico $(\mathrm{R})$ :

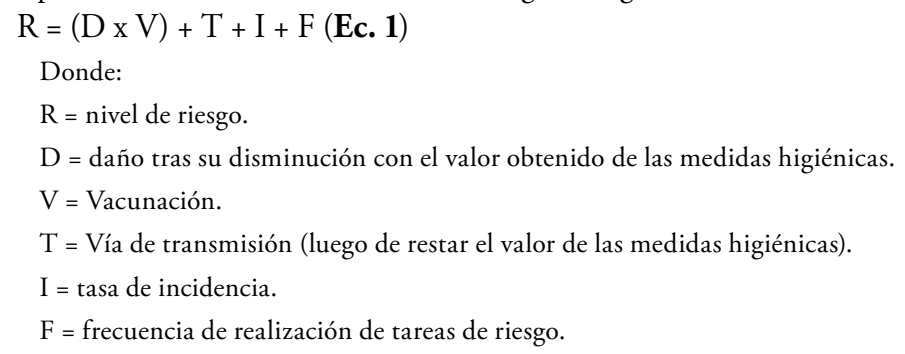

C.8. Finalmente, se procederá a realizar la interpretación de los niveles de riesgo biológico:

- Nivel de acción biológica $(\mathrm{NAB}) \leq 12$. Se requieren medidas preventivas.

- Límite de exposición biológica (LEB) $\geq 17$. Nivel de riesgo intolerable.

\section{Resultados y discusión}

Para el primer sondeo se escogieron ocho puntos en la planada de la estación de transferencia. De este sondeo inicial se establecieron los tres puntos críticos E, A y G, por ser aquellos en los que se encontró la mayor cantidad de bacterias coliformes, como se aprecia en la tabla 1 .

Tabla 1. Datos de bacterias coliformes en el perímetro del hangar de clasificación de residuos

\begin{tabular}{lcc}
\hline \multicolumn{1}{c}{ Puntos } & Cajas & Coliformes (UFC/h) \\
\hline Muelle 1 & $\mathrm{E}$ & 832 \\
\hline Muelle 5 & $\mathrm{A}$ & 106 \\
\hline Muelle 7 & $\mathrm{G}$ & 101 \\
\hline Inicio del balcón & $\mathrm{D}$ & 83 \\
\hline Mitad del balcón & $\mathrm{F}$ & 83 \\
\hline Muelle 7-1 & $\mathrm{G} 1$ & 68 \\
\hline Escaleras & $\mathrm{C}$ & 64 \\
\hline $\begin{array}{l}\text { Detrás del galpón } \\
\text { de la estación }\end{array}$ & $\mathrm{B}$ & 58 \\
\hline
\end{tabular}

UFC = unidades formadoras de colonias

Fuente: elaboración propia.

Una vez determinados los puntos críticos de exposición se procedió a realizar los 52 muestreos, y se obtuvieron los resultados que se presentan en la figura 1 . 


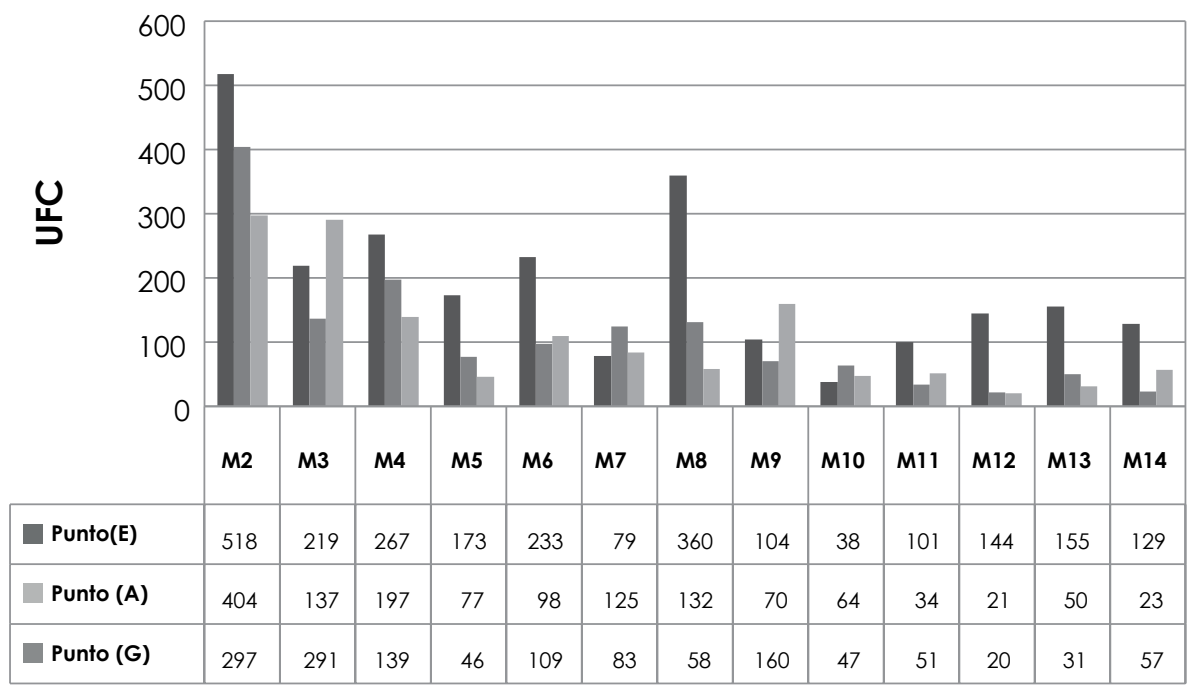

Figura 1. Coliformes totales en las muestras analizadas Fuente: elaboración propia.

Con los datos obtenidos, se procedió a aplicar la ecuación 1 para la determinación del riesgo biológico (R), utilizando la tabla 2.

Tabla 2. Determinación del riesgo biológico en la ET2 por coliformes totales y fecales

\begin{tabular}{cccccccc}
\hline Agente & Enfermedad & Daño & Vacunación & Transmisión & Incidencia & Frecuencia & $\begin{array}{c}\text { Riesgo } \\
\text { biológico }\end{array}$ \\
\hline $\begin{array}{c}\text { Coliformes } \\
\text { totales }\end{array}$ & $\begin{array}{c}\text { Tifoidea y } \\
\text { paratifoidea }\end{array}$ & 2 & 4 & 1 & 1 & 4 & 14 \\
\hline $\begin{array}{c}\text { Coliformes } \\
\text { fecales }\end{array}$ & $\begin{array}{c}\text { Intoxicaciones } \\
\text { alimentarias }\end{array}$ & 1 & 5 & 1 & 1 & 4 & 11 \\
\hline
\end{tabular}

Fuente: elaboración propia.

A partir de la tabla 2, se evaluó el nivel de acción biológica (NAB) si el riesgo es menor o igual a 12 y el límite de exposición biológica (LEB) si el riesgo es mayor o igual a 17. La figura 3 muestra los resultados de esta evaluación. 


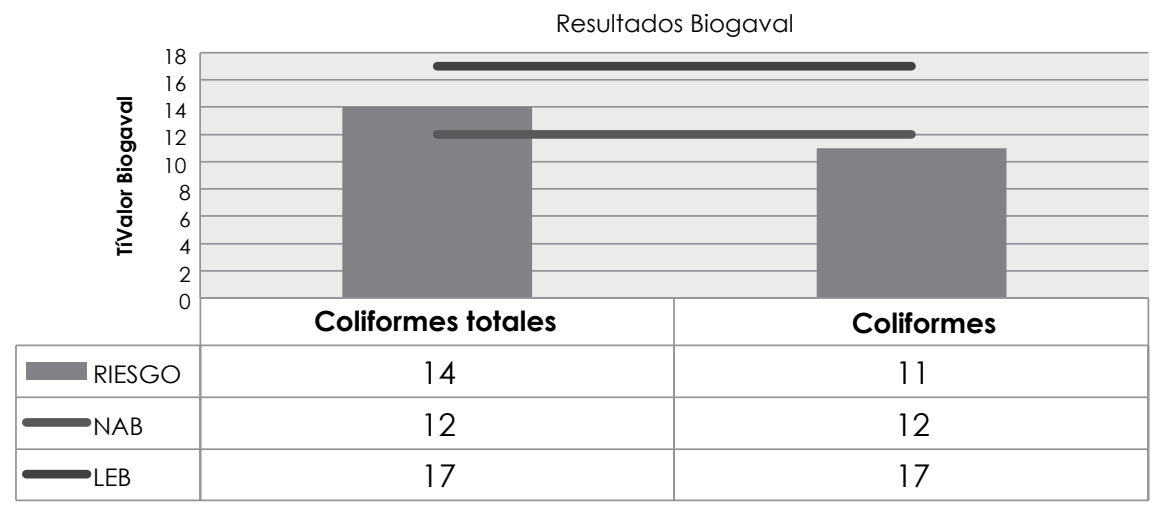

Figura 3. Evaluación del riesgo biológico en la ET2 por coliformes totales y fecales

Fuente: elaboración propia.

Para los coliformes totales y su riesgo concatenado de enfermar a los minadores con tifoidea o paratifoidea, la ET2 presenta un riesgo para nivel de acción biológica (NAB) de 14, superior a lo considerado normal, es decir, que se deben tomar medidas de tipo preventivo para disminuir la exposición, a pesar de que el valor calculado no llega a plantear un riesgo inminente. De cualquier manera, este valor también proporciona información respecto a que se puede efectuar una mejora en el ambiente laboral de los minadores. El riesgo de padecer tifoidea para los minadores se encuentra bajo el límite de exposición biológica en tres unidades.

El riesgo de que los minadores presenten casos de intoxicaciones alimentarias (diarreas agudas) se encuentra justo al límite y presenta un riesgo que involucra medidas sobre el nivel de acción biológica. Este valor conlleva oportunidades de mejorar las condiciones de higiene de los minadores de la ET2.

La basura que llega a la ET2 tiene variada composición química, y por su permanente contacto con sustancias en proceso de degradación, heces, papeles con heces, materiales contaminados, etcétera, es el principal foco de contaminación biológica. Paralelamente, es la fuente de sustento de los minadores de la estación de transferencia.

El material particulado sedimentable, al deponerse, contaminará las zonas expuestas de piel de los minadores, así como sus ropas e implementos de trabajo. Si se toma en cuenta que los minadores comen en el mismo lugar, se concluye que ingieren estas bacterias, con sus respectivas consecuencias.

La evaluación a través del método de Biogaval permitió establecer que el mayor riesgo biológico lo presentan los coliformes totales, con su gran variedad de tipos bacterianos.

A pesar de lo anterior, el conteo de coliformes totales y la presencia de coliformes fecales no fueron abundantes. Sin embargo, se debe resaltar que, al haberse limitado este estudio a las bacterias coliformes, la perspectiva de riesgo biológico se restringe. Un barrido más amplio de virus y bacterias en la ET2 proporcionará una visión más amplia del riesgo biológico. Los resultados obtenidos son, lamentablemente, parciales, pues apenas se analizaron dos agentes patógenos en el ambiente de trabajo. Otras patógenos como Salmonella, Brucella, Clostridium difteriae, Shigella spp., Estreptococo y otros establecidos en el Biogaval, no han sido estudiados en este trabajo, por lo que es recomendable continuar con esta línea de investigación, sobre todo con Salmonella, que junto con los coliformes totales son los principales causantes de la tifoidea y de la paratifoidea.

Las enfermedades reportadas por el Biogaval 2013 para coliformes totales y fecales son la tifoidea y las intoxicaciones alimentarias (diarreas agudas). Y las dos enfermedades son de reporte obligatorio 
en el Ecuador. En los registros del 2013 y del 2014 del Ministerio de Salud se registran los siguientes: tifoidea, veintiún casos de incremento entre el 2013 y el 2014, en tanto que para las intoxicaciones alimentarias (diarreas agudas) se presentó un decremento en el mismo periodo. Esto es un indicativo de que la vacunación en el caso de la tifoidea y el cuidado higiénico para las intoxicaciones alimentarias (diarreas agudas) están siendo efectivos para el control de estas enfermedades en el Ecuador. A pesar de ello y por las condiciones en las que se desenvuelven, el grupo investigador considera poco probable que los minadores estén incluidos en este conteo. Es necesario recalcar que los valores utilizados para la evaluación fueron los correspondientes a la provincia de Pichincha, debido a que la ET2 se encuentra en la ciudad de Quito.

Se comprobó que el factor climatológico influye en el muestreo y, consecuentemente, en el conteo bacteriano. Cuando había presencia de precipitación en el sector norte de la ciudad, las cajas Petri expuestas, al momento de verificar los resultados en el laboratorio, presentaban un menor número de coliformes totales y fecales. Esto se debe a que al estar los residuos sólidos mojados, desprenden menor cantidad de material particulado, el cual precipita inmediatamente por la gran cantidad de humedad superficial presente.

La tendencia mundial es la recuperación y valorización de los residuos, previamente a su disposición final. Esta es una cuenta pendiente de la ciudad de Quito hasta el año 2017. La clasificación y recolección diferenciada de los RSU en la ciudad mejorará notablemente la calidad de vida de los minadores que se ubican en la ET2 y permitirá aumentar sus ingresos, gracias a la mejor calidad de residuos recuperados que podrán obtener. Adicionalmente, desde el Gobierno Autónomo Descentralizado del Distrito Metropolitano de Quito se deben desarrollar políticas de reciclaje y recuperación, utilizando como fuerza laboral a los mismos minadores, para no crear conflictos sociales con este delicado grupo humano.

\section{Medidas técnicas para control del riesgo biológico}

Las medidas para el control del riesgo biológico (tabla 3) comprenden programas de vigilancia sanitaria en tres áreas:

- Foco de emisión del contaminante

- Medio de propagación

- Receptor.

El control de riesgo biológico debe realizarse con el mismo orden de prioridad, es decir, se debe actuar en primer lugar sobre el foco emisor y en último lugar sobre el receptor (CHST, 2014).

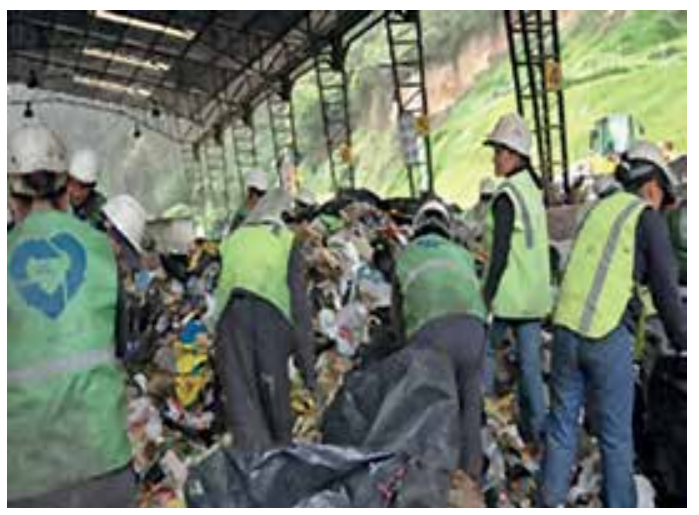

Figura 4. Actividad de minado actual

Fuente: elaboración propia. 


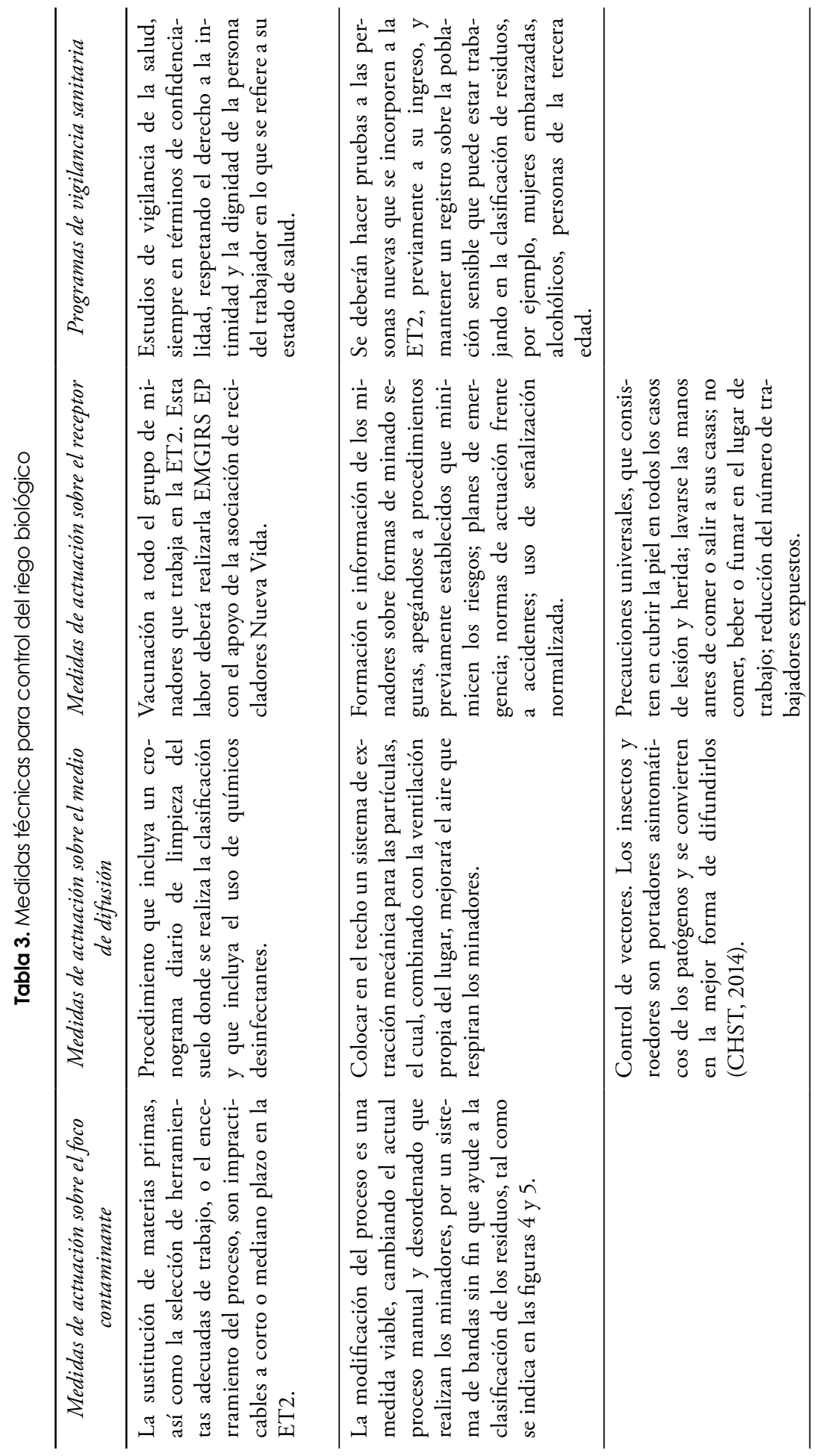




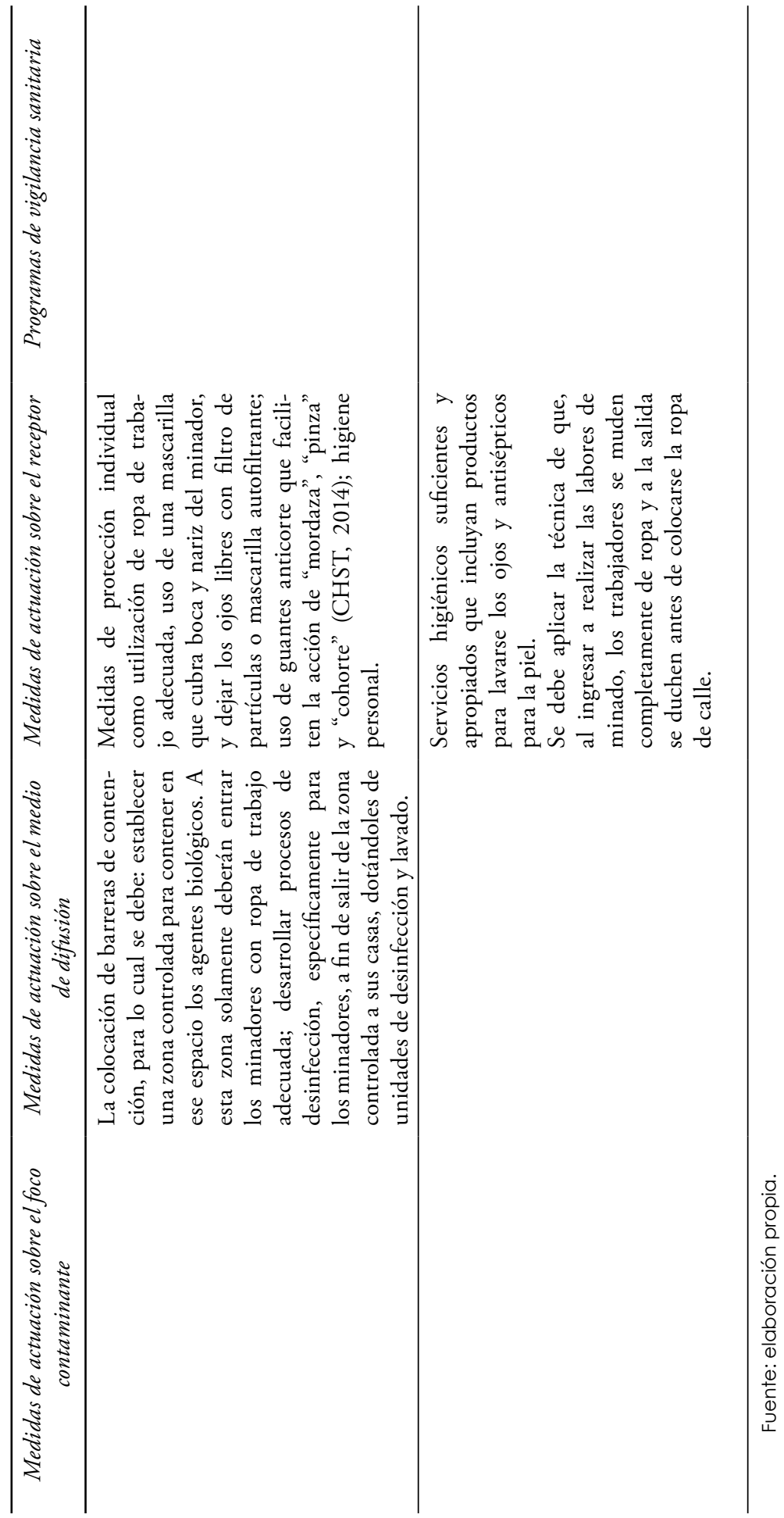




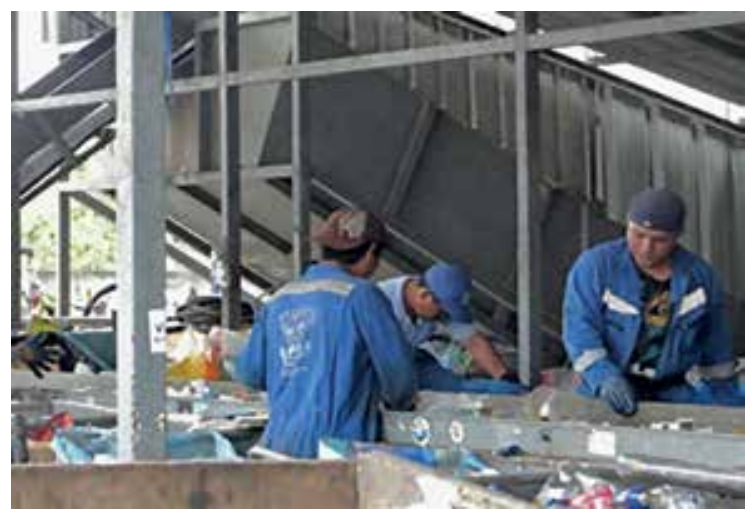

Figura 5. Sugerencia de sistema para modificar el proceso de minado y disminuir el riesgo biológico

Fuente: elaboración propia.

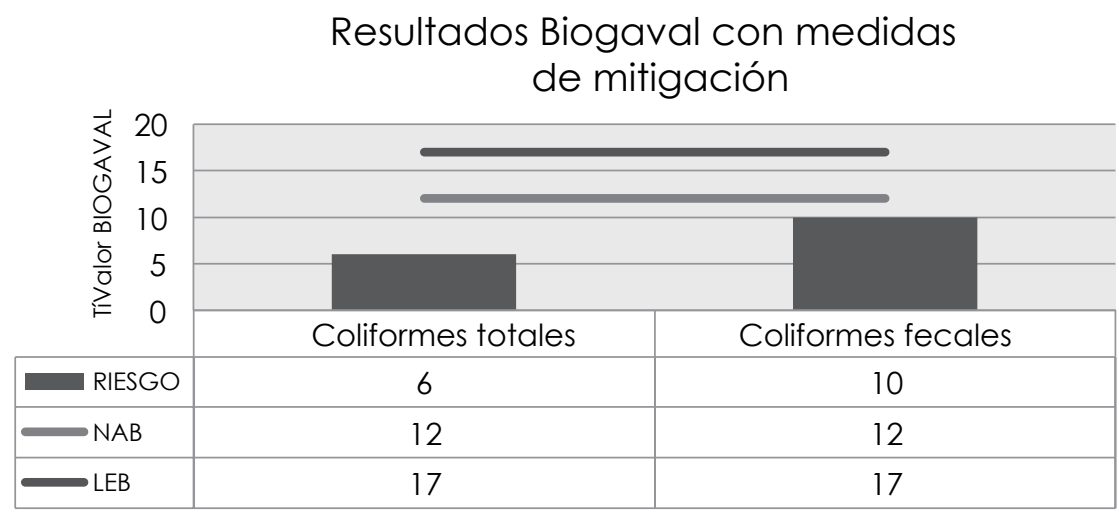

Figura 6. Riesgo biológico con medidas de mitigación

Fuente: elaboración propia.

\section{Conclusiones}

Los resultados obtenidos del monitoreo microbiológico presentan coliformes totales en todas las muestras. Se puede observar que el punto E, correspondiente al muelle 1, ubicado al inicio del galpón, es aquel donde, en la mayoría de los casos, se presentan valores superiores de coliformes, debido a que allí también se acumula la mayor cantidad de basura después del depósito de los camiones recolectores.

De las 208 muestras analizadas, un $19 \%$ presentan cualitativamente coliformes fecales, en tanto que el $100 \%$ de estas presentan conteo de coliformes totales, lo que ratifica que en el ambiente laboral de la ET2 existe la presencia de estos patógenos. 
El promedio de coliformes totales en las mediciones es de $137 \mathrm{col} / \mathrm{cm}$, verificadas a través de conteo en las cajas Petri, por lo tanto, los minadores están en contacto con estos patógenos a través de su aire respirable, del contacto cutáneo e incluso de la ingestión.

En días y fechas festivas, como es el caso de fiestas de Quito, Navidad o vacaciones escolares, se evidenció claramente el aumento de conteo de coliformes totales y fecales, debido a que en estas fechas se incrementa notablemente el volumen de residuos. En consecuencia, se puede concluir que la cantidad de residuos es directamente proporcional a la cantidad de microorganismos presentes en el aire respirable de la ET2.

Los minadores de la ET2 presentan riesgo biológico a coliformes totales y fecales y pueden padecer tifoidea y paratifoidea, así como diarreas agudas. Estos datos es importante compararlos con datos epidemiológicos que permitan determinar los grupos vulnerables dentro de los 220 gestores artesanales, lo que debe ser motivo de una nueva investigación.

Luego de evaluar las medidas de control del riesgo biológico, y en el supuesto de que se aplicaran las recomendaciones técnicas, se encuentra que el riesgo biológico, sobre todo en el caso de la tifoidea, ha disminuido drásticamente. En consecuencia, con las medidas higiénicas adecuadas se puede controlar este factor en cualquier ámbito de trabajo.

Con la aplicación de las medidas correctivas, los valores de NAB y LEB disminuyen hasta no requerir acción sobre ellos, lo que demuestra que es viable y oportuno tomar las medidas explicadas. Sin embargo, queda claro que estas medidas son efectivas para los microorganismos estudiados, y debe realizarse el análisis, la evaluación y el control para cada nuevo patógeno investigado.

Bajar el tiempo de permanencia de los minadores en el proceso de minado se dificulta, pues lo que consigan recuperar entre los residuos es su medio de sustento. Si se acortan sus periodos de exposición (acortándoles su oportunidad de minado), habrá reclamos e incumplimientos, por lo que se hace necesario proporcionar a esta población alternativas de trabajo a través de la capacitación en temas variados que los impulsen a cambiar de actividad.

\section{Referencias}

Agencia Europea para la Seguridad y Salud en el Trabajo. (2007). Agentes biológicos: necesidad de disponer de límites de exposición profesional y viabilidad de establecerlos. Madrid: AESST.

Biogaval. (2013). Manual práctico para la evaluación del riesgo biológico en actividades laborales diversas. Valencia: Generalitat Valenciana, Conselleria D’Economia, Hicenda, I Ocupació.

Construction Health and Safety Technician (CHST). (2014). Candidate Handbook. Illinois, A BCSP Publication.

Dónate, A., Herrero, M. J., Ibáńez, M. y Solera, J. S. (2000). Muestreo de aire, con placa de contacto o con placa Petri. Técnicas de Laboratorio, 22(256), 770-773.

Empresa Pública Metropolitana de Aseo de Quito. (EMASEO EP). (2010). Plan de servicios de aseo y administración zonal Eloy Alfaro. Quito: SMMA.

Empresa Pública Metropolitana de Gestión Integral de Residuos Sólidos. (EMGIRS EP). (2013). Operaciones: Empresa Pública Metropolitana de Gestión Integral de Residuos Sólidos. Recuperado de http://www. emgirs.gob.ec/index.php/operaciones/relleno-sanitario

Esteban, J. (2012). Diagnóstico de las infecciones en tiempo real. Madrid: Instituto de Investigación Sanitaria, Fundación Jiménez Díaz, Universidad Autónoma de Madrid.

Instituto Nacional de Seguridad e Higiene en el Trabajo. (INSHT). (2005). NTP 608: agentes bológicos, planificación de la medición. Madrid: autor. 
Instituto Navarro de Seguridad Laboral. (INSL). (2013). Protección de los trabajadores contra los riesgos relacionados con la exposición a agentes biológicos durante el trabajo. Pamplona, España: autor.

Koneman, E. y Allen S. (2008). Diagnóstico microbiológico. Buenos Aires: Médica Panamericana.

Rodellar, A. (1999). Seguridad e higiene en el trabajo. Bogotá: Alfaomega-Marcombo.

Rodríguez, E., Gamboa, M., Hernández, F. y García, J. (2005). Bacteriología general: principios y prácticas de laboratorio. San José: Editorial Universidad de Costa Rica. 